\title{
Responses of Mytilus galloprovincialis to bacterial challenges by metabolomics and proteomics
}

\author{
Chenglong Ji ${ }^{\mathrm{a}, \mathrm{b}}$, Huifeng $\mathrm{Wu}^{\mathrm{a}, *}$, Lei Wei ${ }^{\mathrm{a}, \mathrm{b}}$, Jianmin Zhao ${ }^{\mathrm{a}}$, Qing Wang ${ }^{\mathrm{a}}$, Hongjian $\mathrm{Lu}^{\mathrm{c}}$ \\ ${ }^{a}$ Key Laboratory of Coastal Zone Environmental Processes, Yantai Institute of Coastal Zone Research (YIC), Chinese Academy of Sciences (CAS), Shandong \\ Provincial Key Laboratory of Coastal Zone Environmental Processes, YICCAS, Yantai 264003, PR China \\ ${ }^{\mathrm{b}}$ The Graduate School of Chinese Academy of Sciences, Beijing 100049, PR China \\ ${ }^{\mathrm{C}}$ Institute of Chemistry and BioMedical Sciences (ICBMS), Nanjing University, Nanjing 210046, PR China
}

\section{A R T I C L E I N F O}

\section{Article history:}

Received 28 March 2013

Received in revised form 26 April 2013

Accepted 6 May 2013

Available online 24 May 2013

\section{Keywords:}

Proteomics

Metabolomics

Bacteria

Mytilus galloprovincialis

Gill

\section{Introduction}

The outbreaks of bacterial diseases can cause massive moralities of marine aquaculture bivalve mollusks and lead to significant losses of production and economic values [1]. Therefore studies on the biological responses and their mechanisms are necessary, which can probably provide useful information for disease control strategies. Traditionally, however, immunity studies on marine aquaculture animals focus on the identification of a certain class of immune-related molecules and then characterize their functions in the immune network, which usually can provide primary but comprehensive understanding on the immune mechanisms [2]. To achieve an insightful and comprehensive understanding on the responsive mechanisms, a global analysis on the biological responses and corresponding

\footnotetext{
* Corresponding author. Tel.: +86 535 2109190; fax: +86 5352109000

E-mail address: hfwu@yic.ac.cn (H. Wu).
}

biomarkers should be carried out in marine aquaculture animals to bacterial challenges at molecular levels (e.g., protein and metabolite).

In this post-genomic era, several system biology approaches such as transcriptomics, proteomics and metabolomics have been well-established and developed [3-5]. Among these approaches, proteomics can theoretically profile all the proteins encoded by the given genome in an organism [6]. Not only can proteomics describe a complete proteome at organelle, cell, or tissue levels, but it can also compare the protein profiles from different treatments and can then identify changes in protein expression levels combined with mass spectrometry and software databases [7]. The twodimensional electrophoresis (2-DE)-based proteomics remains useful in resolving protein extracts from organisms due to its high resolution and low expense [8,9]. Metabolomics can be used to characterize metabolic profiles in various biological systems including organs, tissues, biofluids, or even whole organisms $[10,11]$. Similar to proteomics, comparisons on metabolomes can discover metabolic responses induced by stressors in organisms $[12,13]$. Since metabolomics and proteomics can directly 
characterize the perturbations of metabolic pathways and linked enzymes and stress-responsive proteins, an integration of these two '-omics' techniques can present an insightful view into the stressor-induced responses [14]. To our knowledge, very few investigations have been carried out to test the responses induced by bacteria in marine aquaculture animals using an integrated proteomic and metabolomic approach.

The marine mussel Mytilus galloprovincialis is widely distributed along the Bohai coast. Since it is popularly consumed as seafood by local residents, this bivalve has become one of important species in marine aquaculture industry in China. As a filter-feeder, M. galloprovincialis can accumulate a large amount of bacteria from the seawater and therefore is often used in immunity studies as an experimental model [2]. Routinely, both hepatopancreas and hemocytes of marine bivalves are used in immunology [2]. However, gills are the first organ interacting with the bacteria in the surrounding water and have been also studied in shellfish immunology together with hepatopancreas and hemocytes $[15,16]$. Therefore, in this work, the mussel gill was used for proteomic and metabolomic analysis on the responses to bacterial challenges.

Bacteria are the most commonly detectable pathogens for marine animals. As a Gram-negative bacterium, Vibrio anguillarum is the dominant pathogen for marine aquaculture animals along the Bohai coast in China. This bacterium can also be isolated from marine mollusks. The immunity responses toward $V$. anguillarum have been extensively studied in different marine invertebrates $[2,6]$. Micrococcus luteus is a representative Gram-positive bacterium which can be found in both aquatic and soil environments as well as in aquatic organisms [17]. Several studies have compared the responses in mussel M. galloprovincialis to both Gram-positive and Gram-negative bacterial challenges at molecular level $[2,18]$. In this work, we combined proteomics and metabolomics to compare the responsive profiles in gill tissues from $M$. gall oprovincialis challenged by $V$. anguillarum and M. luteus. This work was designed to elucidate the differential effects of these two representative Gram-positive and Gram-negative bacteria injected in M. galloprovincialis.

\section{Materials and methods}

\subsection{Experimental animals and conditions}

Adult mussels $M$. galloprovincialis (shell length: $5.5-6.0 \mathrm{~cm}$, $n=24$ ) were purchased from a culturing farm (Yantai, China) in July 2012. Animals were transported to the laboratory and acclimatized in aerated natural seawater (salinity $31 \mathrm{psu}$ ) for $10 \mathrm{~d}$. After acclimatization, the animals were randomly separated into four groups (blank, PBS control, V. anguillarum and $M$. luteus challenges) each containing 6 mussels in 12 L filtered seawater. The culture seawater was renewed daily. During the acclimation and experimental periods, mussels were kept at $25^{\circ} \mathrm{C}$ under a photoperiod of $12 \mathrm{~h}$ light and $12 \mathrm{~h}$ dark, and fed with the Chlorella vulgaris Beij at a ration of $2 \%$ tissue dry weight daily.

\subsection{Challenge experiment}

For challenge experiment, live $V$. anguillarum and $M$. luteus were re-suspended in PBS, respectively. These two species of bacteria, $V$. anguillarum (1A07299) and M. luteus (1A00376), were purchased from Marine Culture Collection of China. Each mussel of bacteria-challenged groups was injected with $V$. anguillarum and $M$. luteus in $50 \mu \mathrm{L}$ PBS in the adductor muscle with a final con-

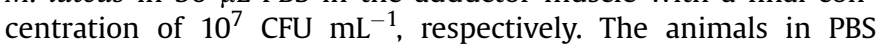
control group were injected with $50 \mu \mathrm{L}$ PBS. The group without any treatment was used as blank group. For injection, each mussel was poked slightly at the edge of the shells. Then the PBS or bacteria solution was injected carefully into the adductor muscle using a syringe. After injections, all the mussels were put back to the tanks and collected at $24 \mathrm{~h}$ post-injection. The gill tissue of each mussel was dissected quickly and flash-frozen in liquid nitrogen, and then stored at $-80{ }^{\circ} \mathrm{C}$ before protein, RNA and metabolite extraction. For further procedures, each treatment consisted of 6 and 3 (2 pooled into 1) replicates for metabolomic and proteomic analysis, respectively.

\subsection{Protein extraction}

Total protein extraction was applied based on the published method with some modifications [19,20]. Briefly, the gill tissue was homogenized quickly on ice with $1 \mathrm{ml}$ Trizol reagent and centrifuged at $12000 \mathrm{~g}$ for $5 \mathrm{~min}$ at $4^{\circ} \mathrm{C}$. The supernatant was added with $200 \mu \mathrm{L}$ chloroform before shaking vigorously for $3 \mathrm{~min}$ and precipitating for $3 \mathrm{~min}$. Then the mixture was centrifuged at $12000 \mathrm{~g}$ for $15 \mathrm{~min}$ at $4{ }^{\circ} \mathrm{C}$ and its upper aqueous layer was discarded. $300 \mu \mathrm{L}$ of absolute ethyl alcohol was added and the mixture was allowed to stand for $3 \mathrm{~min}$ in room temperature before being centrifuged at $2000 \mathrm{~g}$ for $5 \mathrm{~min}$ at $4{ }^{\circ} \mathrm{C}$. The phenol/ethanol supernatant was precipitated for $30 \mathrm{~min}$ at room temperature by the addition of $750 \mu \mathrm{L}$ isopropanol prior to centrifugation at $14000 \mathrm{~g}$ for $10 \mathrm{~min}$ at $4{ }^{\circ} \mathrm{C}$. Pellets obtained were washed with $1 \mathrm{ml}$ ethanol (v/v 95\%) and centrifuged at $14000 \mathrm{~g}$ for $10 \mathrm{~min}$ at $4{ }^{\circ} \mathrm{C}$. This procedure was repeated twice. The pellets were solubilized in the lysis buffer ( $7 \mathrm{M}$ urea; $2 \mathrm{M}$ thiourea; 4\% m/V CHAPS; $65 \mathrm{mM}$ DTT and $0.2 \% \mathrm{~W} / \mathrm{V}$ Bio-lyte buffer) and then incubated for $3 \mathrm{~h}$ at room temperature [21]. The homogenate was centrifuged at $15000 \mathrm{~g}$ for $10 \mathrm{~min}$ and the supernatant was applied to electrophoresis. The total concentrations of proteins were determined by Protein Assay Kit of TianGen.

\subsection{Metabolite extraction}

Polar metabolites in mussel gill tissues ( $n=6$ for each treatment) were extracted by the modified extraction protocol as described previously [22,23]. Briefly, the gill tissue (ca. $100 \mathrm{mg}$ wet weight) was homogenized and extracted in $4 \mathrm{~mL} \mathrm{~g}^{-1}$ of methanol, $5.25 \mathrm{~mL} \mathrm{~g}^{-1}$ of water and $2 \mathrm{~mL} \mathrm{~g}^{-1}$ of chloroform. The methanol/ water layer with polar metabolites was transferred to a glass vial and dried in a centrifugal concentrator. The extracts of gill tissue were then re-suspended in $600 \mu \mathrm{L}$ phosphate buffer $(100 \mathrm{mM}$ $\mathrm{Na}_{2} \mathrm{HPO}_{4}$ and $\mathrm{NaH}_{2} \mathrm{PO}_{4}$, including $0.5 \mathrm{mM}$ TSP, pH 7.0) in $\mathrm{D}_{2} \mathrm{O}$. The mixture was vortexed and then centrifuged at $3000 \mathrm{~g}$ for $5 \mathrm{~min}$ at $4{ }^{\circ} \mathrm{C}$. The supernatant substance $(550 \mu \mathrm{L})$ was then pipetted into a $5 \mathrm{~mm}$ NMR tube prior to NMR analysis.

\subsection{RNA extraction and quantitation of gene expressions}

Total RNA from the gill tissue was isolated following the manufacturer's directions (Invitrogen), and the first-strand cDNA synthesis was carried out according to M-MLV RT Usage information (Promega) using oligo (dT)-adaptor (5'-CTCGAGATCGATGCGG CCGCT17- $3^{\prime}$ ) as primer and the DNase I-treated (Promega) total RNA as template. The expressions of the housekeeping genes (Table 1) in gill of M. galloprovincialis were determined by qRT-PCR, the data were analyzed with geNorm to calculate the expression stability of the genes ( $M$ values) and the optimal number of reference genes required for accurate normalization ( $V$ values) [24]. GeNorm identified $\beta$-actin as the most stable gene, which was lower than the expression stability threshold of 1.5 , then was followed in stability by Glyceraldehyde-3-phosphate dehydrogenase, 
Table 1

The list of primers used for the determination of internal control and quantification of gene expressions by qRT-PCR.

\begin{tabular}{|c|c|c|}
\hline Gene name & Forward primer $\left(5^{\prime}-3^{\prime}\right)$ & Reverse primer $\left(5^{\prime}-3^{\prime}\right)$ \\
\hline \multicolumn{3}{|l|}{ Reference genes: } \\
\hline$\beta$-actin & GCTATCCAGGCCGTACTCT & GCGGTGGTTGTGAATGAG \\
\hline$\alpha$-tubulin & GACCACCCATACCACCCTT & CTCCGTGAGATCGACATTC \\
\hline 18s rRNA & AGAAACGGCTACCACATCC & TGCCCTCCAATAGATCCTC \\
\hline 28s rRNA & CCGAGACCGAGGATTTGCC & ACCGATTCGCCACTGACCC \\
\hline Glyceraldehyde-3-phosphate dehydrogenase & AGGGTCCAATGAAGGGTG & TTAAGAGCGATGCCAGCT \\
\hline \multicolumn{3}{|l|}{ Tested genes: } \\
\hline Nucleoside diphosphate kinase & CTGAACTGACCCATCCTATT & CCTCTTGGTGCATATTGT \\
\hline Goose-type lysozyme 2 & ACATCAATGCTAACCCACT & AAGTTGTATGCAGCTACTCCACCT \\
\hline Glutathione S-transferase sigma 3 & GTGGCGATAAATGGACAG & AATTCACGAGCGAGGTAC \\
\hline Matrilin-2 & AAGACCAATGCTCACCCTC & TTCGCTGTATCCAACCTG \\
\hline Peptidoglycan recognition protein S3 & TCTTATGCCTTGTTTGGAC & TTATTTGGGAGAATGTGC \\
\hline
\end{tabular}

$\alpha$-tubulin, 28s rRNA and 18s rRNA. The results showed that the V2/3 value 0.132 was less than the proposed geNorm cutoff value of 0.15 , which meant that the gene of $\beta$-actin was the most stable gene and was then used as the internal control for gene expression normalization.

Gene-specific primers (Table 1) for selected genes were used to amplify amplicons specific for $M$. galloprovincialis. The fluorescent real-time quantitative PCR amplifications were carried out in triplicate in a total volume of $20 \mu \mathrm{L}$ containing $10 \mu \mathrm{L}$ of $2 \times$ SYBR Premix Ex Taq $^{\mathrm{TM}}$ (TaKaRa), $0.4 \mu \mathrm{L}$ of $50 \times$ ROX Reference DYE II, $4.8 \mu \mathrm{L}$ DEPCtreated $\mathrm{H}_{2} \mathrm{O}, 0.4 \mu \mathrm{L}$ of each primer, $4.0 \mu \mathrm{L}$ of $1: 20$ diluted cDNA. The fluorescent real-time quantitative PCR program was as following: $50{ }^{\circ} \mathrm{C}$ for $2 \mathrm{~min}$ and $95^{\circ} \mathrm{C}$ for $10 \mathrm{~min}$, followed by 40 cycles of $94^{\circ} \mathrm{C}$ for $15 \mathrm{~s}, 58{ }^{\circ} \mathrm{C}$ for $45 \mathrm{~s}, 72{ }^{\circ} \mathrm{C}$ for $30 \mathrm{~s}$. Dissociation curve analysis of amplification products was performed at the end of each PCR to confirm that only one $\mathrm{PCR}$ product was amplified and detected. After the PCR program, data were analyzed with the ABI 7500 SDS software (Applied Biosystems). To maintain consistency, the baseline was set automatically by the software. The comparative CT method $\left(2^{-\Delta \Delta C T}\right.$ method) was used to analyze the expression level of the genes [25].

\subsection{Two-dimensional gel electrophoresis}

The first dimension (IEF) was performed using Immobiline Drystrip (24 cm, pH 3-10, linear). One hundred and forty microgram of proteins to a final volume of $450 \mu \mathrm{L}$ were loaded. Isoelectric focusing gel solution containing $7 \mathrm{M}$ urea, $2 \mathrm{M}$ thiourea, $4 \% \mathrm{~m} / \mathrm{v}$ CHAPS, $65 \mathrm{mM}$ DTT, $0.001 \% \mathrm{~m} / \mathrm{v}$ Bromophenol blue and $0.2 \% \mathrm{~W} / \mathrm{V}$ Bio-lyte buffer. IEF was conducted at $20^{\circ} \mathrm{C}$ with an Etan IPGphor3 system for a total of $85858 \mathrm{Vh}$ (Active rehydration was carried out at $30 \mathrm{~V}$ for $12 \mathrm{~h}$, followed by $100 \mathrm{~V}$ for $5 \mathrm{~h}, 500 \mathrm{~V}$ for $1 \mathrm{~h}, 1000 \mathrm{~V}$ for $1 \mathrm{~h}$, and a linear increase of voltage to $8000 \mathrm{~V}$ for $11 \mathrm{~h}$ ).

After the first dimension, strips were placed in equilibration buffer (0.05 M Tris-HCl, pH 8.8; $6 \mathrm{M}$ urea; 30\% glycerol; 2\% w/v SDS; containing $1 \% \mathrm{w} / \mathrm{v}$ DTT) and were slowly shaken for $15 \mathrm{~min}$. The strips were then incubated for another $15 \mathrm{~min}$ in the equilibration buffer with $2.5 \%(\mathrm{w} / \mathrm{v})$ iodoacetamide without DTT. The second dimension was conducted on 12.5\% SDS-PAGE gels using the Ettan DALTsix system. After electrophoresis, the gels were silver stained by following the published method of Mortz (2001) and Gharahdaghi (1999) [26,27]. Images were captured by ImageScanner III and spots were quantitatively analyzed by using ImageMaster 2D Platinum 7.0. The abundance of each protein spot was estimated by the percentage volume (\%vol). Only those with significant changes ( $>1.5$ folds and $P<0.05$ ) were considered to be differentially expressed proteins.

\subsection{In gel digestion and MS analysis}

In gel digestion was according to Katayama et al. (2001) [28]. Protein spots were washed three times with ultrapure water, de- stained with $25 \mathrm{mmol} / \mathrm{L} \mathrm{NH}_{4} \mathrm{HCO}_{3}$ in $50 \% \mathrm{v} / \mathrm{v}$ acetonitrile at room temperature for $30 \mathrm{~min}$. The gels were dried using $50 \%$ acetonitrile for $30 \mathrm{~min}$ and $100 \%$ acetonitrile for another $30 \mathrm{~min}$. The samples were rehydrated in $10 \mu \mathrm{l}$ cover solution $(0.02 \mathrm{~g} / \mathrm{l} \mathrm{w} / \mathrm{v}$ trypsin, $25 \mathrm{mmol} / \mathrm{L} \mathrm{NH}_{4} \mathrm{HCO}_{3}$ and $10 \%$ acetonitrile) for $30 \mathrm{~min}$, and then covered with the same solution but without trypsin for digestion overnight at $37^{\circ} \mathrm{C}$. The supernatants were extracted with 5\% TFA in $67 \%$ acetonitrile at $37{ }^{\circ} \mathrm{C}$ for $30 \mathrm{~min}$, then were centrifuged at $5000 \mathrm{~g}$ for $5 \mathrm{~min}$, so the peptide extracts and the supernatant of the gel spot were combined.

After being completely dried the samples were re-suspended with $5 \mu \mathrm{L} 0.1 \%$ TFA followed by mixing in $1: 1$ ratio with a saturated solution of $\alpha$-cyano-4-hydroxy-trans-cinnamic acid in $50 \%$ acetonitrile [29]. One microliter of mixture was analyzed by an $A B I$ 4800 MALDI-TOF/TOF Plus mass spectrometer (Applied Biosystems, Foster City, USA), data were acquired in a positive MS reflector using a CalMix5 standard to calibrate the instrument (ABI4800 Calibration Mixture). Both the MS and MS/MS data were integrated and processed by using the GPS Explorer V3.6 software (Applied Biosystems, USA) with default parameters. Proteins were successfully identified based on $95 \%$ or higher confidence interval of their scores in the MASCOT V2.4 search engine (Matrix Science Ltd., London, U.K.). The following parameters were used in the search: NCBInr Metazoa (Animals) (2861494 sequences) database; trypsin as the digestion enzyme; one missed cleavage site; partial modifications of cysteine carbamidomethylation and methionine oxidization; no fixed modifications; 0.15 Da for precursor ion tolerance and $0.25 \mathrm{Da}$ for fragment ion tolerance. Individual ions scores $>40$ indicate identity or extensive homology $(P<0.05)$.

\section{8. ${ }^{1}$ H NMR spectroscopy}

Metabolite extracts of gills from mussels were analyzed on a Bruker AV 500 NMR spectrometer performed at $500.18 \mathrm{MHz}$ (at $25{ }^{\circ} \mathrm{C}$ ) as described previously [30]. All ${ }^{1} \mathrm{H}$ NMR spectra were phased, baseline-corrected, and calibrated (TSP at $0.0 \mathrm{ppm}$ ) manually using TopSpin (version 2.1, Bruker).

\subsection{Spectral pre-processing and multivariate analysis}

All one dimensional ${ }^{1} \mathrm{H}$ NMR spectra were converted to a data matrix using the custom-written ProMetab software in Matlab version 7.0 (The MathsWorks, Natick, MA) [31]. Each spectrum was segmented into bins with a width of $0.005 \mathrm{ppm}$ between 0.2 and $10.0 \mathrm{ppm}$. The bins of residual water peak between 4.70 and $5.20 \mathrm{ppm}$ were excluded from all the NMR spectra. The total spectral area of the remaining bins was normalized to unity to facilitate the comparison between the spectra. All the NMR spectra were generalized log transformed (glog) with a transformation parameter $\lambda=1.0 \times 10^{-8}$ to stabilize the variance across the 
spectral bins and to increase the weightings of the less intense peaks [31]. Data were mean-centered before principal components analysis (PCA) using PLS Toolbox (version 4.0, Eigenvector Research, Manson, WA).

The unsupervised pattern recognition method, principal component analysis (PCA) was used to reduce the dimensionality of the data and summarize the similarities and differences between multiple NMR spectra [32]. The algorithm of this pattern recognition method calculates the highest amount of correlated variation along PC1, with subsequent PCs containing correspondingly smaller amounts of variance. One-way analysis of variance (ANOVA) was conducted on the PC scores from each group to test the statistical significance $(P<0.05)$ of separations. Furthermore, the supervised multivariate data analysis methods, partial least squares discriminant analysis (PLS-DA) and orthogonal projection to latent structure with discriminant analysis (O-PLS-DA), were sequentially carried out to uncover and extract the statistically significant metabolite variations related to bacterial challenges. The results were visualized in terms of scores plots to show the classifications and corresponding loadings plots to show the NMR spectral variables contributing to the classifications. The model coefficients were calculated from the coefficients incorporating the weight of the variables in order to enhance interpretability of the model. Then metabolic differences responsible for the classifications between control and bacteria-challenged groups could be detected in the coefficient-coded loadings plots. The coefficient plots were generated by using MATLAB (V7.0, the Mathworks Inc., Natwick, USA) with an in-house developed program and were color-coded with absolute value of coefficients $(r)$. A hot color (i.e., red) corresponds to the metabolites with highly positive/negative significances in discriminating between groups, while a cool color (i.e. blue) corresponds to no significance. The correlation coefficient was determined according to the test for the significance of the Pearson's product-moment correlation coefficient. The validation of the model was conducted using 10 -fold cross validation and the cross-validation parameter $\mathrm{Q}^{2}$ was calculated, and an additional validation method, permutation test (permutation number $=200$ ), was also conducted in order to evaluate the validity of the PLS-DA models. The $R^{2}$ in the permutated plot described how well the data fit the derived model, whereas $Q^{2}$ describes the predictive ability of the derived model and provides a measure of the model quality. If the maximum value of $Q^{2}$ max from the permutation test was smaller than or equal to the $Q^{2}$ of the real model, the model was regarded as a predictable model. Similarly, the $R^{2}$ value and difference between the $R^{2}$ and $Q^{2}$ were used to evaluate the possibility of over-fitted models [14]. Metabolites were assigned following the tabulated chemical shifts [33] and quantified by using the software, Chenomx (Evaluation Version, Chenomx Inc., Edmonton, Alberta, Canada). The metabolite concentrations were normalized to the mass of hepatopancreas tissue by calculating the concentrations of metabolites in each NMR tube.

\subsection{Statistical analysis}

Metabolite concentrations were tested for normal distribution (Ryan-Joiner's test) and homogeneity of variances (Bartlett's test). All metabolite concentrations were expressed as means \pm standard deviation. One way analysis of variance (ANOVA) with Tukey's test was conducted on the metabolite concentrations from both seawater control (blank) and PBS control groups to test possible metabolic differences induced by PBS in mussel gills. Furthermore, one-way ANOVA combined with Tukey's test was performed on metabolite concentrations between PBS control and bacteria-challenged groups, respectively. A $P$ value less than 0.05 was considered statistically significant. The Minitab software (Version 15, Minitab Inc., USA) was used for the statistical analysis.
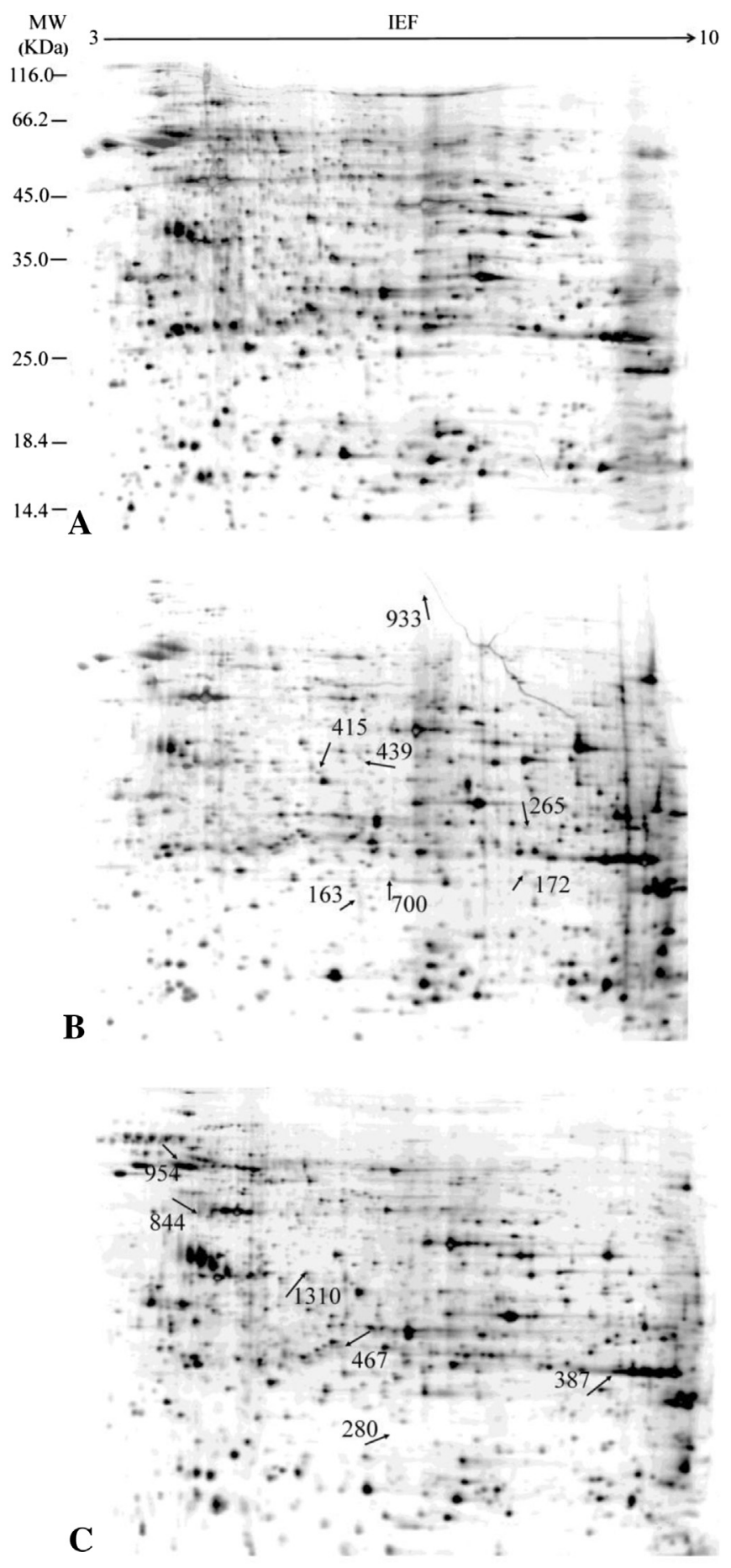

Fig. 1. Representative 2-DE images of proteins from gills of $M$. galloprovincialis. Proteins were submitted to isoelectric focusing on 3-10 IPG strips $(24 \mathrm{~cm})$ followed by electrophoresis on 12.5\% SDS-PAGE. Gels were silver-stained. Gels (A, B and C) were from (A) PBS control, (B) Micrococcus luteus- and (C) Vibrio anguillarum-challenged groups. The numbered arrows indicate proteins that were identified by MS/MS and are listed in Tables 2 and 3.

\section{Results}

3.1. Proteomic responses in gills of M. galloprovincialis challenged by $M$. luteus and $V$. anguillarum

Proteomic responses were determined by 2-DE-based proteomics in gills of $M$. galloprovincialis challenged by $V$. anguillarum 
and $M$. luteus, respectively (Fig. 1). A total of 15 spots resolved in 2DE gels were differentially expressed ( $>1.5$ folds, $P<0.05$ ). Fig. 1 shows the differential protein spots in gills of $M$. galloprovincialis challenged by $M$. luteus and $V$. anguillarum. All the differentially expressed proteins in all three biological replicates of silver-stained gels were analyzed by MALDI-TOF/TOF mass spectrometry and 13 $(\sim 87 \%)$ proteins were successfully identified. The information of these proteins is summarized in Tables 2 and 3.

Firstly, we compared the protein spots in the 2-DE gels from blank and PBS control groups. However, no significant protein spots were found between these two groups. Then only PBS control group was used for further analysis. In M. luteus-challenged samples, a total of 7 significantly differential spots were discovered, including 3 up-regulated and 4 down-regulated. These proteins were related to immune defensive system (goose-type lysozyme 2, peptidoglycan recognition protein S3 and matrilin-2) and signaling pathway (ependymin-related protein 1, receptor of activated kinase C 1 and peptidyl-prolyl cis-trans isomerase).

Six differentially expressed proteins (3 up-regulated and 3 down-regulated) were observed in $V$. anguillarum-challenged $M$. galloprovincialis gills. These proteins were basically involved in primary and energy metabolism (nucleoside diphosphate kinase, astacin, procollagen-proline dioxygenase beta subunit and electron transfer flavoprotein subunit alpha), stress and defense (glutathione S-transferase sigma 3) and signal transduction (ependyminlike protein precursor).

\subsection{Metabolomic responses in gills of M. galloprovincialis challenged by $M$. luteus and $V$. anguillarum}

Fig. 2 shows the representative ${ }^{1} \mathrm{H}$ NMR spectra of gills tissue extracts from PBS control, $M$. luteus and $V$. anguillarum groups. Different classes of metabolites were identified in gill of M. galloprovincialis, including amino acids (valine, leucine, isoleucine, alanine, threonine, glutamate, glycine, etc.), sugars ( $\alpha, \beta$-glucose), osmolytes (betaine, homarine, dimethylglycine, taurine and hypotaurine), intermediates in the Krebs cycle (succinate and fumarate) and energy metabolism-related metabolites (ATP and glucose).

The unsupervised pattern recognition method, principal components analysis (PCA), was conducted on the NMR spectral data matrix of gill extracts from blank, PBS control, $V$. anguillarum- and $M$. luteus-challenged groups. No significant $(P=0.85$, one way ANOVA on PC scores) separation between blank and PBS control groups was found in score plot (PC1 vs. PC2). Then only PBS control group was used in further analysis. Clearly, PCA analysis resulted in significant $(P<0.01)$ separations between PBS control, $M$. luteus and $V$. anguillarum treatments along PC1 axis, as shown in Fig. 3. Furthermore, the significant separation between $V$. anguillarum and $M$. luteus-challenged mussel groups was found as well.

O-PLS-DA and one way ANOVA were performed on the NMR spectral data and quantified metabolite concentrations for metabolic biomarker discovery in $V$. anguillarum- and $M$. luteus-treated groups, respectively (Fig. 4). Apparently, the concentrations of amino acids (valine, leucine, isoleucine and tyrosine), ATP and glucose were significantly $(P<0.05)$ increased in $M$. luteus-challenged mussel gills (Table 4). However, the concentration of betaine was significantly $(P<0.05)$ decreased. Compared to the metabolic profile from $M$. luteus-challenged group, several metabolites were similarly altered including some amino acids (valine, isoleucine, leucine and tyrosine), betaine and glucose. However, elevated threonine, alanine, homarine, succinate and fumarate and depleted aspartate were uniquely detected in $V$. anguillarum-challenged mussel samples. Interestingly, ATP was significantly decreased in $V$. anguillarum-challenged mussel gills, which was contrary to that in M. luteus-challenged mussel samples.

\subsection{The relationship between gene expressions and protein abundances}

To further verify the results of 2-DE and compare the correlation between gene expression and protein abundances, five representative genes related to regulated proteins were quantified using quantitative real-time PCR technique. The results indicated that the expression levels of the genes had different alteration tendency with corresponding proteins (data not shown).

\section{Discussion}

\subsection{Effects of M. luteus and V. anguillarum on the proteome of gills in M. galloprovincialis}

Approximately, 1000 protein spots were resolved in the 2-DE gels from the gill of $M$. galloprovincialis. In M. luteus-challenged mussel samples, the responsive proteins including goose-type lysozyme 2, matrilin 2 and peptidoglycan recognition protein S3 were related to immune defensive system. Fig. 5A summarized the pathways involved in the response of $M$. galloprovincialis to $M$. luteus challenge. Lysozymes are antibacterial enzymes that play

Table 2

List of protein spots which were differentially expressed in M. galloprovincialis gills induced by M. luteus.

\begin{tabular}{|c|c|c|c|c|c|c|c|c|c|}
\hline Spot ID & Protein name & Species & GI number ${ }^{c}$ & $\mathrm{MW} / \mathrm{kDa}^{\mathrm{d}}$ & PI & Protein Score ${ }^{\mathrm{e}}$ & $\mathrm{PN}^{\mathrm{f}}$ & $\mathrm{SC}^{\mathrm{g}}$ & Fold changes $^{h}$ \\
\hline \multicolumn{10}{|l|}{ Defense } \\
\hline 172 & Goose-type lysozyme 2 & Mytilus galloprovincialis & 380860909 & 22704 & 8.06 & 148 & 2 & 16 & $1.53^{a}$ \\
\hline 265 & Peptidoglycan recognition protein S3 & Crassostrea gigas & 238643834 & 22596 & 8.08 & 37 & 2 & 22 & $-1.90^{\mathrm{a}}$ \\
\hline 933 & Matrilin-2 & Crassostrea gigas & 223021902 & 22574 & 7.15 & 91 & 4 & 44 & $-2.25^{\mathrm{a}}$ \\
\hline \multicolumn{10}{|c|}{ Signal transduction and protein synthesis } \\
\hline 163 & Ependymin-related protein 1 & Crassostrea gigas & 238643097 & 24391 & 6.87 & 49 & 2 & 20 & $2.88^{\mathrm{a}}$ \\
\hline 439 & Receptor of activated kinase $\mathrm{C} 1$ & Mya arenaria & 115501910 & 35534 & 6.54 & 141 & 4 & 16 & $1.72^{\mathrm{a}}$ \\
\hline 700 & Peptidyl-prolyl cis-trans isomerase B-like & Mytilus californianus & 145895362 & 40235 & 6.78 & 80 & 4 & 17 & $-3.22^{\mathrm{a}}$ \\
\hline \multicolumn{10}{|c|}{ Unclassified } \\
\hline 415 & DPY30 domain-containing protein 1 & Crassostrea gigas & 223023829 & 14671 & 5.84 & 109 & 2 & 13 & $-1.62^{\mathrm{a}}$ \\
\hline
\end{tabular}

a Identification of differentially expressed proteins in $M$. galloprovincialis gills between control and Vibrio anguillarum-challenged groups, and between control and Micrococcus luteus-challenged groups, respectively.

b Assigned spot ID as indicated in Fig. 3.

c Database GI numbers after searching against the NCBInr database.

d Experimental mass.

e Mascot score reported.

f Number of peptide sequences.

g Sequence coverage.

h Fold changes with significant changes $(>1.5$ folds and $P<0.05)$ were calculated using ImageMaster 2D Platinum 7.0. 
Table 3

List of protein spots which were differentially expressed in M. galloprovincialis gills induced by V. anguillarum.

\begin{tabular}{|c|c|c|c|c|c|c|c|c|c|}
\hline Spot ID & Protein name & Species & GI number ${ }^{c}$ & $\mathrm{MW} / \mathrm{kDa}^{\mathrm{d}}$ & PI & Protein Score ${ }^{\mathrm{e}}$ & $\mathrm{PN}^{\mathrm{f}}$ & $\mathrm{SC}^{\mathrm{g}}$ & Fold changes $^{h}$ \\
\hline \multicolumn{10}{|c|}{ Energy and primary metabolism } \\
\hline 280 & Nucleoside diphosphate kinase & Ostrea edulis & 223023089 & 23039 & 6.51 & 45 & 5 & 22 & $-1.59^{\mathrm{a}}$ \\
\hline 844 & Astacin & Crassostrea gigas & 238638946 & 30495 & 4.19 & 79 & 3 & 18 & $2.34^{\mathrm{a}}$ \\
\hline 954 & Procollagen-proline dioxygenase beta subunit & Mytilus galloprovincialis & 390979785 & 55402 & 4.53 & 466 & 8 & 20 & $4.88^{\mathrm{a}}$ \\
\hline 1310 & Electron transfer flavoprotein subunit alpha & Bombus terrestris & 340727666 & 35324 & 4.29 & 94 & 2 & 7 & $-1.88^{\mathrm{a}}$ \\
\hline \multicolumn{10}{|l|}{ Defense } \\
\hline 387 & Glutathione S-transferase sigma 3 & Mytilus galloprovincialis & 145887704 & 34657 & 8.46 & 86 & 2 & 6 & $1.83^{\mathrm{a}}$ \\
\hline \multicolumn{10}{|c|}{ Signal transduction and protein synthesis } \\
\hline 467 & Ependymin-like protein precursor & Saccoglossus kowalevskii & 238643167 & 23217 & 5.85 & 144 & 2 & 12 & $-1.78^{\mathrm{a}}$ \\
\hline
\end{tabular}

a Identification of differentially expressed proteins in M. galloprovincialis gills between control and Vibrio anguillarum-challenged groups.

b Assigned spot ID as indicated in Fig. 3.

c Database GI numbers after searching against the NCBInr database.

d Experimental mass.

e Mascot score reported.

${ }^{\mathrm{f}}$ Number of peptide sequences.

g Sequence coverage.

h Fold changes with significant changes $(>1.5$ folds and $P<0.05)$ were calculated using ImageMaster 2D Platinum 7.0.,.

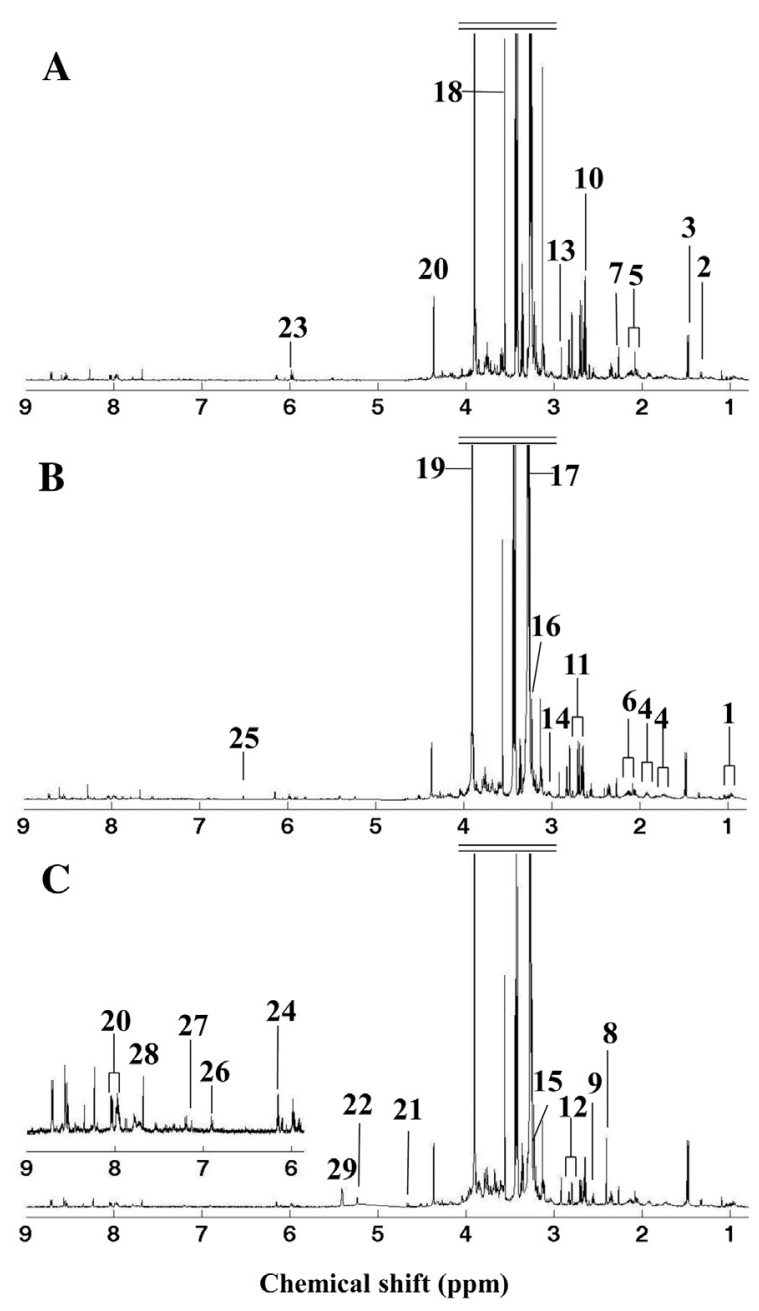

Fig. 2. Representative 1-dimensional $500 \mathrm{MHz}{ }^{1} \mathrm{H}$ NMR spectra of tissue extracts from gills of M. galloprovincialis from (A) solvent control, (B) M. luteus- and (C) $V$. anguillarum-challenged groups. Keys: (1) branched chain amino acids: valine, leucine and isoleucine, (2) threonine, (3) alanine, (4) arginine, (5) glutamate, (6) glutamine, (7) acetoacetate, (8) succinate, (9) $\beta$-alanine, (10) hypotaurine, (11) aspartate, (12) asparagine, (13) dimethylglycine, (14) lysine, (15) choline, (16) phosphocholine, (17) taurine, (18) glycine, (19) betaine, (20) homarine, (21) $\beta$-glucose, (22) $\alpha$-glucose, (23) unknown 1 (5.98 ppm), (24) ATP, (25) fumarate, (26) tyrosine, (27) histidine, (28) unknown 2 (7.68 ppm) and (29) glycogen.

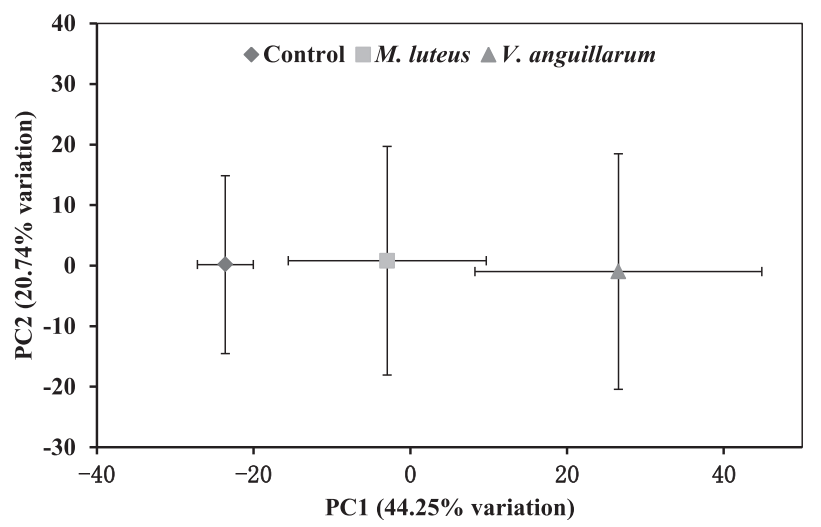

Fig. 3. Mean principal component analysis (PCA) scores plot of $\mathrm{PC} 1 \mathrm{vs}$. PC2 for ${ }^{1} \mathrm{H}$ NMR spectra of tissue extracts from gills of $M$. galloprovincialis from PBS control, M. luteusand $V$. anguillarum-challenged groups. The classes were presented as mean \pm standard deviation (as associated standard error) of PC scores for each group of mussel samples.

important roles in the immune system by cleaving the $\beta$ - $(1,4)$ glycosidic bond between $\mathrm{N}$-acetylmuramic acid and $\mathrm{N}$-acetylglucosamine in peptidoglycan layer of bacterial cell walls. In our laboratory, we have studied two goose-type lysozymes in M. galloprovincialis and characterized their possible function diversification and adaptive evolution [34]. Our results demonstrated that goose-type lysozyme 2 played an important role in digestion indicated by the significantly increased expression level after bacterial challenges [35]. Matrilin is a subfamily of extracellular matrix proteins that are involved in immune defense [35]. Peptidoglycan recognition protein belongs to a family of innate immune proteins that possesses bactericidal effect against Grampositive bacteria [36]. The alteration of these three immunityrelated proteins clearly exhibited the immune stress of $M$. luteus in M. galloprovincialis.

Ependymin-related proteins constitute a family of extracellular glycoproteins that are often found in vertebrates [37]. However, recent studies have discovered ependymin-related proteins in invertebrates, such as abalones [38]. Ependymin-related protein 1 was significantly up-regulated in gills of $M$. galloprovincialis challenged by $M$. luteus. This protein is postulated to be involved in intracellular signaling [39]. Peptidyl-prolyl cis-trans isomerases (PPIase) can catalyze the cis-trans isomerization of peptide bonds on the amino-terminal side of proline [40]. It has been thought to be essential for protein folding during protein synthesis in the cell 

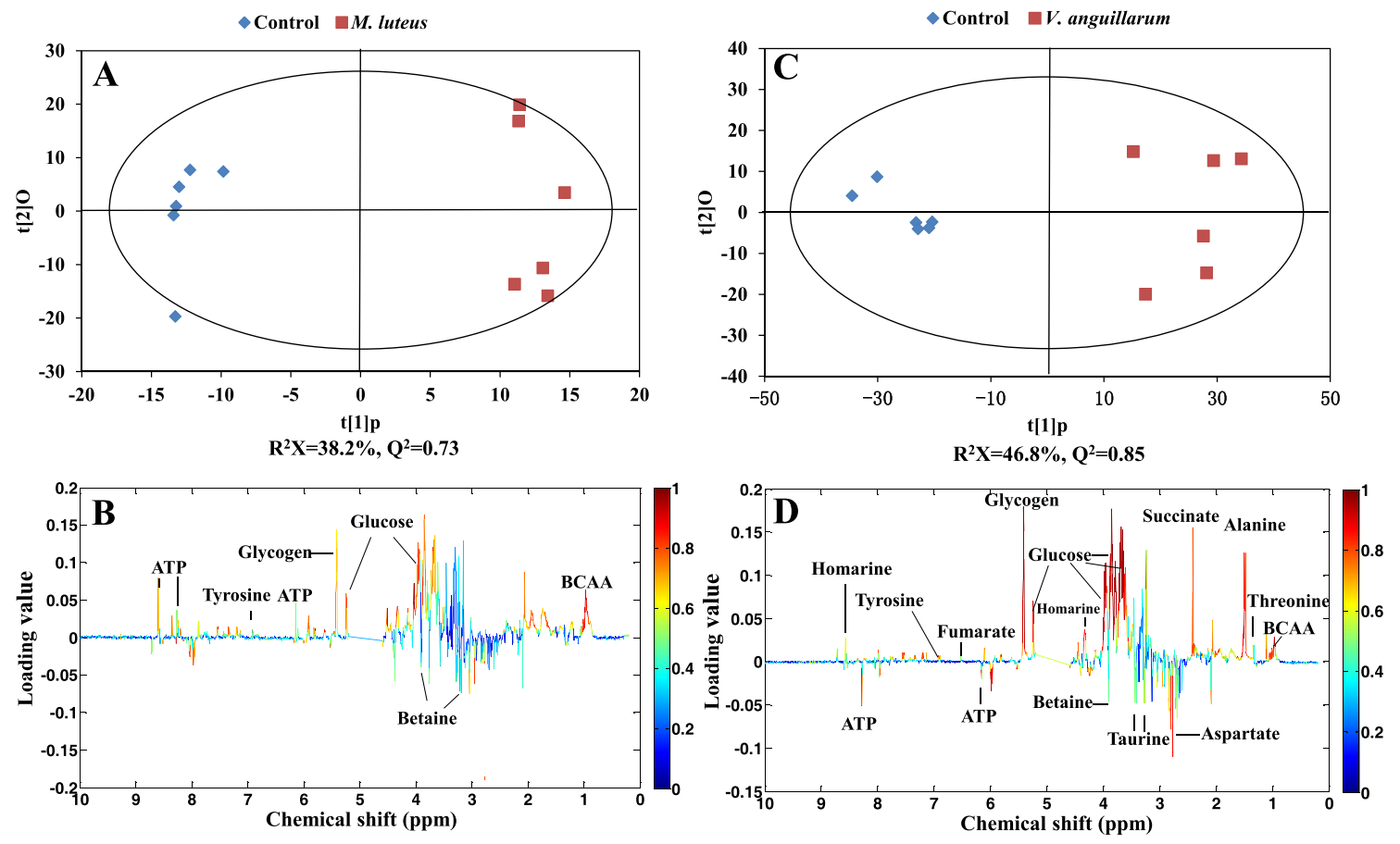

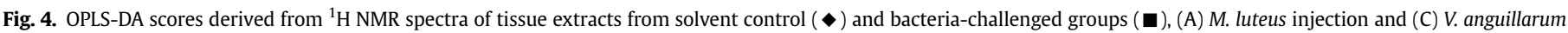



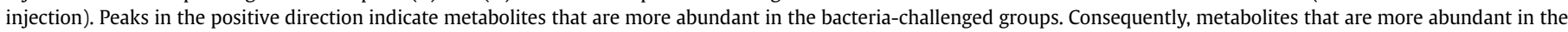

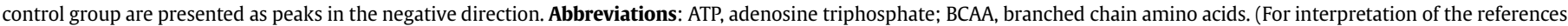
to color in this figure legend, the reader is referred to the web version of this article.)

[40]. The down-regulation of PPIase might imply the disturbance in protein synthesis in $M$. luteus-challenged mussel samples. Receptor for activated kinase C (RAKC) is involved in signal transduction, RNA processing and cell cycle processing and has been recognized as an immunogenic protein [41]. The up-regulated RAKC implied the immune stress in gills of mussel challenged by M. luteus.

In $V$. anguillarum challenged-mussel samples, a total of six proteins were significantly altered. Fig. 5B summarized the

Table 4

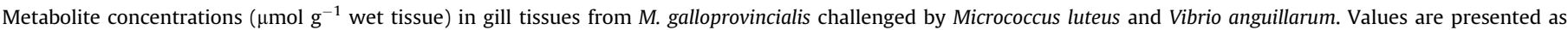
mean \pm standard deviation $(n=6)$.

\begin{tabular}{|c|c|c|c|c|}
\hline \multirow[t]{2}{*}{ Metabolites } & \multirow[t]{2}{*}{ Chemical shift (ppm, multiplicity) } & \multicolumn{3}{|l|}{ Challenges } \\
\hline & & Control & M. luteus & V. anguillarum \\
\hline Valine & $1.05(\mathrm{~d})$ & $0.080 \pm 0.016$ & $0.105 \pm 0.008^{b}$ & $0.114 \pm 0.017^{b}$ \\
\hline Isoleucine & $1.00(\mathrm{~d})$ & $0.052 \pm 0.009$ & $0.069 \pm 0.006^{b}$ & $0.091 \pm 0.021^{b}$ \\
\hline Leucine & $0.94(\mathrm{t})$ & $0.047 \pm 0.010$ & $0.092 \pm 0.013^{b}$ & $0.093 \pm 0.017^{b}$ \\
\hline Threonine & $1.34(\mathrm{~d})$ & $0.155 \pm 0.042$ & $0.189 \pm 0.054$ & $0.233 \pm 0.052^{a}$ \\
\hline Alanine & $1.48(\mathrm{~d})$ & $1.445 \pm 0.549$ & $1.422 \pm 0.581$ & $2.482 \pm 0.413^{b}$ \\
\hline Arginine & $1.70(\mathrm{~m})$ & $0.675 \pm 0.114$ & $0.783 \pm 0.193$ & $0.782 \pm 0.119$ \\
\hline Glutamate & $2.05(\mathrm{~m})$ & $1.634 \pm 0.346$ & $1.642 \pm 0.109$ & $1.746 \pm 0.248$ \\
\hline Glutamine & $2.14(\mathrm{~m})$ & $0.221 \pm 0.071$ & $0.245 \pm 0.058$ & $0.247 \pm 0.077$ \\
\hline Acetoacetate & $2.26(\mathrm{~s})$ & $0.566 \pm 0.212$ & $0.524 \pm 0.096$ & $0.524 \pm 0.104$ \\
\hline Succinate & $2.41(\mathrm{~s})$ & $0.102 \pm 0.135$ & $0.081 \pm 0.054$ & $0.429 \pm 0.174^{b}$ \\
\hline$\beta$-Alanine & $2.55(\mathrm{t})$ & $0.439 \pm 0.156$ & $0.467 \pm 0.178$ & $0.490 \pm 0.154$ \\
\hline Hypotaurine & $2.66(t)$ & $3.257 \pm 1.316$ & $3.048 \pm 0.397$ & $2.547 \pm 0.409$ \\
\hline Dimethylglycine & $2.91(\mathrm{~s})$ & $0.186 \pm 0.067$ & $0.172 \pm 0.080$ & $0.123 \pm 0.057$ \\
\hline Aspartate & $2.68(\mathrm{ABX})$ & $6.030 \pm 0.453$ & $5.381 \pm 0.700$ & $4.015 \pm 0.588^{b}$ \\
\hline Lysine & $3.03(t)$ & $0.250 \pm 0.042$ & $0.229 \pm 0.065$ & $0.230 \pm 0.039$ \\
\hline Choline & $3.21(\mathrm{~s})$ & $0.208 \pm 0.098$ & $0.130 \pm 0.066$ & $0.157 \pm 0.064$ \\
\hline Phosphocholine & $3.22(\mathrm{~s})$ & $0.327 \pm 0.051$ & $0.369 \pm 0.069$ & $0.302 \pm 0.075$ \\
\hline Taurine & $3.27(\mathrm{t})$ & $39.881 \pm 1.440$ & $38.786 \pm 1.910$ & $35.253 \pm 1.767^{b}$ \\
\hline Betaine & $3.91(\mathrm{~s})$ & $34.989 \pm 1.528$ & $32.790 \pm 1.387^{a}$ & $31.372 \pm 1.119^{b}$ \\
\hline Glycine & $3.56(\mathrm{~s})$ & $6.746 \pm 2.050$ & $6.057 \pm 1.401$ & $7.123 \pm 1.138$ \\
\hline Glucose & $4.64(\mathrm{~d}), 5.24(\mathrm{~d})$ & $0.377 \pm 0.349$ & $2.085 \pm 1.164^{a}$ & $3.652 \pm 1.667^{b}$ \\
\hline Homarine & $4.37(\mathrm{~s})$ & $6.550 \pm 1.011$ & $5.744 \pm 0.511$ & $7.584 \pm 0.272^{a}$ \\
\hline ATP & $6.15(\mathrm{~d})$ & $0.389 \pm 0.090$ & $0.638 \pm 0.076^{b}$ & $0.252 \pm 0.061^{b}$ \\
\hline Fumarate & $6.52(\mathrm{~s})$ & $0.009 \pm 0.005$ & $0.014 \pm 0.007$ & $0.019 \pm 0.006^{a}$ \\
\hline Tyrosine & $6.91(\mathrm{~d})$ & $0.061 \pm 0.015$ & $0.092 \pm 0.018^{b}$ & $0.116 \pm 0.018^{b}$ \\
\hline Histidine & $7.12(\mathrm{~s})$ & $0.103 \pm 0.032$ & $0.103 \pm 0.031$ & $0.107 \pm 0.027$ \\
\hline
\end{tabular}

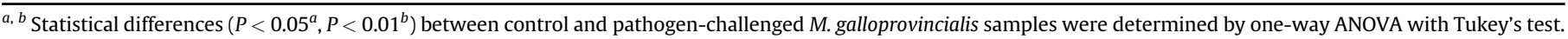


A



Fig. 5. Schematic presentations of molecular responsive-mechanisms in gills from $M$. galloprovincialis challenged by $M$. luteus (A) and $V$. anguillarum (B) according to Kyoto Encyclopedia of Genes and Genomes (http://www.genome.jp/kegg/) and Uniprot (http://www.uniprot.org/). The identified proteins and metabolites were shown by marking the names in red (up-regulated) or blue (down-regulated). Abbreviation: ETF: electron transfer flavoprotein; GST: glutathione S-transferase; GTL: goose-type lysozyme; NDK: nucleoside diphosphate kinase; PKC: protein kinase C; PPD: procollagen-proline dioxygenase; PPIase: peptidyl-prolyl cis-trans isomerase; PRP: peptidoglycan recognition protein; RAKC, receptor of activated kinase C. (For interpretation of the references to color in this figure legend, the reader is referred to the web version of this article.)

proteomic and metabolomic responses involved in the pathways. Nucleoside diphosphate kinases (NDKs) are enzymes that catalyze the exchange of phosphate groups between various nucleoside diphosphates. For example, NDKs can convert guanosine triphosphate (GTP) to ATP in Krebs cycle [42]. However, the level of ATP was significantly $(P<0.05)$ elevated (Table 4$)$. Since ATP can be biosynthesized in various metabolic pathways catalyzed by different enzymes, such as ATP synthetases and NDKs, the inconsistency between ATP and NDK changes was not strange. Electron transfer flavoprotein (ETF) is an important enzyme involved in mitochondrial energy metabolism by receiving electrons from at least 11 dehydrogenases operating in fatty acid oxidation, amino acid and choline metabolism [43]. The down-regulation of NDK and ETF subunit alpha clearly indicated the disturbance in energy metabolism from mussel gills with $V$. anguillarum treatment. Procollagen-proline dioxygenase is a mixed-function oxygenase catalyzing the hydroxylation of a prolyl-glycyl-containing-peptide to a hydroxyprolylglycyl-containing-peptide and resulting in an increase of succinate [44]. The beta subunit of procollagen-proline dioxygenase belongs to the family of protein disulfide isomerases (PDI) catalyzing the formation and breakage of disulfide bonds between sulfides (S-) in cysteine residues of folding proteins. As a member of the superfamily of thioredoxin, PDI has been found in response to oxidative stress [45]. In $V$. anguillarum-challenged mussel samples, procollagen-proline dioxygenase beta subunit was the most significantly up-regulated protein, which probably implied the oxidative stress induced by $V$. anguillarum injection. Astacin (EC 3.4.24.21) is a prototype for the family of zincdependent endopeptidases, which play crucial role in extracellular proteolysis during tissue development, bone growth, morphogenesis, digestion and cell migration [46]. The up-regulated astacin implied the disturbance in extracellular protein metabolism in anguillarum-challenged mussel gills. Glutathione S-transferases (GSTs) are related to the reduction of reactive oxygen species (ROS) production. Huan et al. (2011) reported that V. anguillarum challenge induced a significant up-regulation of GST in hepatopancreas of Zhikong scallop Chlamys farreri [6]. In this study, an upregulation of GST sigma 3 was similarly observed in mussel gills, indicating the oxidative stress induced by $V$. anguillarum injection in mussel gills, as mentioned above. The down-regulated ependymin-like protein precursor might be related to the altered signaling pathway.

\subsection{Effects of M. luteus and $V$. anguillarum on the metabolome of gills in M. galloprovincialis}

PCA analysis resulted in significant $(P<0.01)$ separations between PBS control, M. luteus- and V. anguillarum-challenged mussel groups along PC1 axis (Fig. 3). It clearly demonstrated the significant metabolic differences between PBS control and bacteriachallenged groups. Moreover, the significant $(P<0.01)$ separation between $V$. anguillarum- and $M$. luteus-challenged groups indicated that $V$. anguillarum and $M$. luteus induced different biological effects in mussel gills.

In $M$. luteus-challenged mussel samples, several amino acids (valine, leucine, isoleucine and tyrosine) were significantly $(P<0.05)$ increased. Marine mollusks can employ high concentrations of amino acids to regulate their intracellular osmolarity with their environment [47]. An organic osmolyte, betaine, was significantly decreased. Therefore the alteration in amino acids and betaine indicated the disturbance in osmotic regulation. In addition, the levels of two energy storage metabolites, glucose and ATP, were significantly increased, which clearly exhibited the disturbance in energy metabolism.

For the $V$. anguillarum-challenged mussel group, four amino acids (valine, isoleucine, leucine, and tyrosine), betaine and glucose were altered similarly to those in M. luteus-challenged mussel group. These metabolic biomarkers suggested that both bacteria could induce similar biological effects in mussel gills. In addition, some other metabolites, including threonine, alanine, aspartate, taurine, homarine, succinate and fumarate, were uniquely altered. 
Obviously, the elevated amino acids (threonine and alanine) and homarine, and depleted taurine suggested the more severe osmotic stress in $V$. anguillarum-challenged mussel samples. However, the level of ATP was significantly $(P<0.01)$ decreased in $V$. anguillarumchallenged mussel group. It is postulated that mussels consumed more energy to deal with the more severe osmotic stress induced by $V$. anguillarum injection, indicated by the depleted ATP. Two intermediates in Krebs cycle, succinate and fumarate were significantly increased and aspartate was significantly decreased in $V$. anguillarum-challenged mussel gills. In addition, the elevation in succinate could be related to the up-regulation of procollagenproline dioxygenase, as mentioned above. In one possible metabolic pathway, aspartate could be converted into succinate with no detectable changes in other compounds under anoxic conditions in mollusk resulting in the decreased aspartate and increased succinate [48]. Therefore the decreased aspartate and increased succinate meant the enhancement of anaerobiosis in mussel gills challenged by $V$. anguillarum.

\subsection{Correlation between gene expressions and protein abundances}

To further evaluate the correlation between gene expression and protein abundances, the expressions of five genes corresponding to (NDK, goose-type lysozyme 2, glutathione S-transferase sigma 3, matrilin-2 and peptidoglycan recognition protein S3) in M. galloprovincialis were quantified to explore the correlation between protein and corresponding mRNA expression levels. However, the results indicated that mRNA expressions did not correlate well with the protein abundances (data not shown). The disparity between mRNA and corresponding protein expressions was not surprising [49], since mRNA expression means the tendency of the corresponding encoded protein which does not always happen due to the posttranscriptional and posttranslational modifications [49,50].

In summary, the molecular responses induced by M. luteus and $V$. anguillarum, were investigated by metabolomics and proteomics in gills of mussel M. galloprovincialis. Both metabolomic and proteomic biomarkers indicated the differential responses of mussel gills to $M$. luteus and $V$. anguillarum challenges. Overall, both $M$. luteus and $V$. anguillarum induce disturbances in energy metabolism and osmotic regulation as indicated by altered amino acids, betaine, ATP, glucose. However, $V$. anguillarum caused more severe disturbances in osmotic regulation and energy metabolism. In addition, $M$. luteus caused immune stress and disturbance in signaling pathways demonstrated by altered goose-type lysozyme 2 , matrilin, ependymin-related protein and peptidyl-prolyl cistrans isomerases. However, V. anguillarum mainly induced oxidative stress and disturbance in energy metabolism in mussel gills. Our results indicated that a combination of proteomics and metabolomics was robust to elucidate the effects of pathogens to the marine mussel M. galloprovincialis.

\section{Acknowledgment}

This work was supported by The 100 Talents Program of the Chinese Academy of Sciences.

\section{References}

[1] Paillard C, Leroux F, Borrego JJ. Bacterial disease in marine bivalves: review of recent studies. Trends and evolution. Aquat Living Resour 2004;17:477-98.

[2] Costa MM, Prado-Alvarez M, Gestal C, Li H, Roch P, Novoa B, et al. Functional and molecular immune response of Mediterranean mussel (Mytilus galloprovincialis) haemocytes against pathogen-associated molecular patterns and bacteria. Fish Shellfish Immunol 2009;26:515-23.
[3] Santos EM, Ball JS, Williams TD, Wu H, Ortega F, van Aerle R, et al. Identifying health impacts of exposure to copper using transcriptomics and metabolomics in a fish model. Environ Sci Technol 2010;44:820-6.

[4] Nesatyy VJ, Suter MJF. Proteomics for the analysis of environmental stress responses in organisms. Environ Sci Technol 2007;41:6891-900.

[5] Li Z, Wu H, Zhang X, Li X, Liao P, Li W, et al. Investigation on the acute biochemical effects of light rare earths (lanthanum and cerium) by NMRbased metabonomic approaches. Chem J Chin Univ 2006;27:438-42.

[6] Huan P, Wang H, Liu B. Comparative proteomic analysis of challenged Zhikong scallop (Chlamys farreri): a new insight into the anti-vibrio immune response of marine bivalves. Fish Shellfish Immunol 2011;31:1186-92.

[7] Lemos MFL, Soares AMVM, Correia AC, Esteves AC. Proteins in ecotoxicology how, why and why not? Proteomics 2010;10:873-87.

[8] Choi J-W, Liu H, Song H, Park JHY, Yun JW. Plasma marker proteins associated with the progression of lung cancer in obese mice fed a high-fat diet. Proteomics 2012;12:1999-2013.

[9] Liu H, Choi J-W, Yun JW. Gender differences in rat plasma proteome in response to high-fat diet. Proteomics 2012;12:269-83.

[10] Lindon JC, Nicholson JK, Everett JR. NMR spectroscopy of biofluid. Ann Rep NMR Spectros 1999;38:1-88.

[11] Davis B. Growing pains for metabolomics. The Scientist 2005;19:25-8.

[12] Wu H, Zhang X, Li X, Li Z, Wu Y, Pei F. Comparison of metabolic profiles from serum from hepatotoxin-treated rats by nuclear-magnetic-resonancespectroscopy-based metabonomic analysis. Anal Biochem 2005;340:99-105.

[13] Pedras MSC, Zheng QA. Metabolic responses of Thellungiella halophila/salsuginea to biotic and abiotic stresses: metabolite profiles and quantitative analyses. Phytochemistry 2010;71:581-9.

[14] Zhang H, Ding L, Fang X, Shi Z, Zhang Y, Chen H, et al. Biological responses to perfluorododecanoic acid exposure in rat kidneys as determined by integrated proteomic and metabonomic studies. PLoS One 2011;6:e20862.

[15] Matozzo V, Giacomazzo M, Finos L, Marin MG, Bargelloni L, Milan M. Can ecological history influence immunomarker responses and antioxidant enzyme activities in bivalves that have been experimentally exposed to contaminants? A new subject for discussion in "eco-immunology" studies. Fish Shellfish Immunol 2013. http://dx.doi.org/10.1016/j.fsi.2013.04.013.

[16] Luna-Acosta A, Saulnier D, Pommier M, Haffner P, De Decker S, Renault T, et al. First evidence of a potential antibacterial activity involving a laccase-type enzyme of the phenoloxidase system in Pacific oyster Crassostrea gigas haemocytes. Fish Shelliish Immunol 2011;31:795-800.

[17] Spanggaard B, Huber I, Nielsen EB, Pipper CB, Martinussen T, Slierenecht WJ, et al. The probiotic potential against vibriosis of the indigenous microflora of rainbow trout. Environ Microbiol 2001;3:755-65.

[18] Li H, Parisi M-G, Toubiana M, Cammarata M, Roch P. Lysozyme gene expression and hemocyte behaviour in the Mediterranean mussel, Mytilus galloprovincialis, after injection of various bacteria or temperature stresses. Fish Shellfish Immunol 2008;25:143-52.

[19] Lee SC, Chan J, Clement MV, Pervaiz S. Functional proteomics of resveratrolinduced colon cancer cell apoptosis: caspase-6-mediated cleavage of lamin A is a major signaling loop. Proteomics 2006;6:2386-94.

[20] Kirkland PA, Busby J, Stevens Jr S, Maupin-Furlow JA. Trizol-based method for sample preparation and isoelectric focusing of halophilic proteins. Anal Biochem 2006;351:254-9.

[21] Tullius MV, Phillips NJ, Scheffler NK, Samuels NM, Munson Jr RS, Hansen EJ, et al. The $\operatorname{lbg} A B$ gene cluster of Haemophilus ducreyi encodes $\alpha \beta-1$, 4-galactosyltransferase and an $\alpha-1,6$-DD-heptosyltransferase involved in lipooligosaccharide biosynthesis. Infect Immun 2002;70:2853-61.

[22] Wu H, Southam AD, Hines A, Viant MR. High throughput tissue extraction protocol for NMR and mass spectrometry based metabolomics. Anal Biochem 2008;372:204-12.

[23] Lin CY, Wu H, Tjeerdema RS, Viant MR. Evaluation of metabolite extraction strategies from tissue samples using NMR metabolomics. Metabolomics 2007;3:55-67.

[24] Dang W, Sun L. Determination of internal controls for quantitative real time RT-PCR analysis of the effect of Edwardsiella tarda infection on gene expression in turbot (Scophthalmus maximus). Fish Shellfish Immunol 2011;30:720-8.

[25] Livak KJ, Schmittgen TD. Analysis of relative gene expression data using realtime quantitative PCR and the 2(-Delta Delta $C(T)$ ) method. Methods 2001;25:402-8.

[26] Mortz E, Krogh TN, Vorum H, Gorg A. Improved silver staining protocols for high sensitivity protein identification using matrix-assisted laser desorption/ ionization-time of flight analysis. Proteomics 2001;1:1359-63.

[27] Gharahdaghi F, Weinberg CR, Meagher DA, Mische SM. Mass spectrometric identification of proteins from silver-stained polyacrylamide gel: a method for the removal of silver ions to enhance sensitivity. Electrophoresis 1999;20: 601-5.

[28] Katayama H, Nagasu T, Oda Y. Improvement of in-gel digestion protocol for peptide mass fingerprinting by matrix-assisted laser desorption/ionization time-of-flight mass spectrometry. Rapid Commun Mass Spectrom 2001;15: 1416-21.

[29] Shevchenko A, Wilm M, Vorm O, Mann M. Mass spectrometric sequencing of proteins from silver-stained polyacrylamide gels. Anal Chem 1996;68:850-8.

[30] Liu X, Zhang L, You L, Yu J, Zhao J, Li L, et al. Differential toxicological effects induced by mercury in gills from three pedigrees of Manila clam Ruditapes philippinarum by NMR-based metabolomics. Ecotoxicology 2011;20:177-86. 
498

C. Ii et al. / Fish E' Shellfish Immunology 35 (2013) 489-498

[31] Parsons HM, Ludwig C, Gunther UL, Viant M. Improved classification accuracy in 1- and 2-dimensional NMR metabolomics data using the variance stabilising generalised logarithm transformation. BMC Bioinformatics 2007;8:234.

[32] Xu L. Methods of chemometrics. Beijing: Science Press; 2004. p. 221-7.

[33] Fan WMT. Metabolite profiling by one- and two-dimensional NMR analysis of complex mixtures. Prog Nucl Man Reson 1996;28:161-219.

[34] Wang Q, Zhang L, Zhao J, You L, Wu H. Two goose-type lysozyme in Mytilus galloprovincialis: possible function diversification and adaptive evolution. PLoS One 2012;7:e45148.

[35] Bouchut A, Roger E, Cousteau C, Gourbal B, Nita G. Compatibility in the Biomphalaria glabrata/Echinostoma caproni model: potential involvement of adhesion genes. Int J Parasitol 2006;36:175-84.

[36] Ito N, Takahashi KG. A novel peptidoglycan recognition protein containing a goose-type lysozyme domain from the Pacific oyster, Crassostrea gigas. Mol Immunol 2009;46:1768-74.

[37] Hoffman W, Schwarz H. Ependymins: meningeal-derived extracellular matrix proteins at the blood-brain barrier. Int Rev Cytol 1996;165:121-58.

[38] Marie B, Marie A, Jackson DJ, Dubost L, Degnan BM, Mile C, et al. Proteomic analysis of the organic matrix of the abalone Haliotis asinine calcified shell. Proteome Sci 2010;8:54. http://dx.doi.org/10.1186/1477-5956-8-54.

[39] Gregorio-King CC, McLeod JL, Collier FM, Collier GR, Bolton KA, Van Der Meir GJ, et al. MERP1: a mammalian ependymin-related protein gene differentially expressed in hematopoietic cells. Gene 2002;286:249-57.

[40] Gothel SF, Marahiel MA. Peptidylprolyl cis-trans isomerases, a superfamily of ubiquitous folding catalysts. Cell Mol Life Sci 1999;55:423-36.

[41] Ruszczyk A, Joerink M, Guldenaar C, Hermsen T, Savelkoul HFJ, Wiegertjes GF. cDNA expression library screening and identification of two novel antigens: ubiquitin and receptor for activated $\mathrm{C}$ kinase (RACK) homologue, of the fish parasite Trypanosoma carassii. Fish Shellfish Immunol 2008;25:84-90.

[42] Leyva JA, Bianchet MA, Amzel LM. Understanding ATP synthesis: structure and mechanism of the F1-ATPase (Review). Mol Membr Biol 2003;20:27-33.

[43] Watmough NJ, Freeman FE. The electron transfer flavoprotein: ubiquinone oxidoreductases. Biochim Biophys Acta 2010;1797:1910-6.

[44] Berg RA, Prockop DJ. Affinity column purification of protocollagen proline hydroxylase from chick embryos and further characterization of the enzyme. J Biol Chem 1973;248:1175-82.

[45] Freedman RB, tHirst TR, Trite MF. Protein disulphide isomerase: building bridges in protein folding. Trends Biochem Sci 1994;19:331-6.

[46] Geier G, Zwilling R. Cloning and characterization of a cDNA coding for Astacus embryonic astacin, a member of the astacin family of metalloproteases from the crayfish Astacus astacus. Eur J Biochem 1998;253:796-803.

[47] Viant MR, Rosenblum ES, Tjeerdema RS. NMR-based metabolomics: a powerful approach for characterizing the effects of environmental stressors on organism health. Environ Sci Techno 2003;37:4982-9.

[48] Graham RA, Ellington WR. Phosphorus nuclear magnetic resonance studies of energy metabolism in molluscan tissues: intracellular $\mathrm{pH}$ change and the qualitative nature of anaerobic end products. Physio Zool 1985;58: 478-90.

[49] Wang X, Chang L, Sun Z, Chang Y. Comparative proteomic analysis of differentially expressed proteins in the earthworm Eisenia fetid during Escherichia coli 0157:H7 stress. J Proteome Res 2010;9:6547-60.

[50] Yon SP, Zhang QY, Tang ZC, Bu WA, Sun WN. Comparative proteomics analysis provides new insights into chilling stress responses in rice. Mol Cell Proteomics 2006;5:484-96. 